\title{
HYGIENE AND SANITATION RISK FACTORS OF DIARRHEAL DISEASE IN CHILDREN UNDER FIVE YEARS OLD ADMITTED TO DR. JAMAL AHMAD RASHID PEDIATRIC TEACHING HOSPITAL IN SULAIMANI CITY
}

\author{
Tavga Akram Salam ${ }^{1}$, Bahar Nasradeen Majeed 2 * \\ 1. Kurdistan Centre for Gastroenterology \& Hepatology (KCGH), Sulaimani, Kurdistan, Iraq. \\ 2. Department of clinical nursing, College of Nursing, University of Sulaimani, City of Sulaimani, Iraq.
}

\author{
Corresponding author: Tavga Akram Salam \\ Email: Tav.akram@gmail.com
}

ORCID

\section{ABSTRACT}

Background: Acute diarrhea in children under the age of five is the leading cause of morbidity and mortality worldwide. It is important to identify factors associated with diarrhea in order to develop appropriate preventative and therapeutic approaches

Aim: To assess hygiene and sanitation risk factors of diarrheal disease in children under five years old admitted to Dr. Jamal Ahmad Rashid Pediatric Teaching Hospital in Sulaimani City.

Methods: A quantitative design (descriptive study) case control approach was used, data collected from the period 3rd of March to 3rd of June 2021 at Dr. Jamal Ahmed Rashid Pediatric Teaching Hospital in Sulaimani City, using a nonprobability purposive sample technique to select (105) children diagnosed with acute diarrhea as case group, and (105) non diarrheal children as a control group in outpatients unit in same hospital. Researcher collected the data by direct interview with mothers, data were analyzed by using the statistical package for social science (SPSS) version 21.

Results: Out of 105 diarrheal groups $42.9 \%$ of mothers their age between $25-34$ years old, 39\% were graduated from primary school, $86.7 \%$ were unemployed, $55.3 \%$ were insufficient, $62.9 \%$ were in urban area, and $74.3 \%$ of their families consist of less than five members. $49.5 \%$ of children their age were 12 months or younger, 53.3\% were male, 34.3\% were second birth order, $69.5 \%$ were normal birth weight, and $89.5 \%$ were complete vaccination. Significant association were found between mother age, level of education, child age, gender, methods of cleaning child after defecating, mother washing hands after toilet, after cleaning child perineum, before feeding child, methods of storing food for later use with diarrhea.

Conclusions: Young and low educated mother, low family income, infant age, male gender, poor hygiene practice, were the main risk factors of diarrhea. To minimize the rate of childhood diarrhea, there is a need to improve awareness of mothers regarding sanitation and personal hygiene and rotavirus vaccination.

Keywords: Nursery, Training program, First Aid

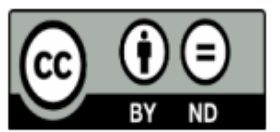

This work is licensed under a Creative Commons Attribution Non-Commercial 4.0 International License.

Received: 20 May 2021, Accepted: 15 July 2021, Available online: 20 January 2022 


\section{INTRODUCTION}

The World Health Organization (WHO) defines diarrhea as three or more watery or loose stools per day, or stools that are more frequent than normal in an individual (WHO, 2017). Diarrhea can be classified clinically as acute diarrhea if it lasts for a few days and is either watery or bloody, or as persistent diarrhea if it lasts for two weeks or longer. Severe diarrhea can cause electrolyte and fluid loss, which can lead to serious complications or even death, especially in malnourished children (Black et al., 2008).

Diarrhea in children is one of the most important diseases that health centers focus on because it can lead to loss of life for children if they do not receive the required health care and fastest action (Walker et al., 2013). It is a leading cause of morbidity and mortality in children under the age of five in developing countries. Each year, over 1.5 million children die as a result of diarrhea. Among the leading causes of death of children of under five ages worldwide diarrhoea remains the second (UNICEF/WHO, 2009). However, study conducted in a pediatrics teaching hospital in Sulaimni city by Rashid et al., (2009) revealed that prematurity was the main cause of death among neonates, and diarrhea diseases were the main causes of death during infancy.

Despite improvements in standard of living, advances in sanitation, water treatment, and food safety awareness, diarrheal illness continues to cause major economic and societal losses. (Reddington et al., 2014). Although there has been a reduction in overall worldwide mortalities due to diarrhea over the previous several decades, morbidity from diarrhea may not have exhibited a similar decline (Kosek et al., 2003).

Iraq is a developing country that has seen the horrors of wars and sanctions for more than two decades. As in all wars the most susceptible group is children, especially on their health, because of the lack of proper nutrition, sanitation, and immunization, there is serious widespread diarrhea (Alam et al., 2000). Previously many studies in cities of Iraq indicate that improper breast feeding, water supply, poor hygiene and sanitation, low income, crowdedness, and low mother education are important risk factors for occurrences of diarrhea (Alaa et al., 2014; Harbetal.,2017; Al-Kubaisy et al., 2015; Siziyaetal.,2009; Lafta et al.,2019; Shamki et al.,2012; Rahi et al., 2013) however, we are still facing a lot of cases of acute diarrhea and its complication in every day practice (Tuky and Semender, 2019).
For the effective prevention of diarrheal diseases, it is necessary to understand risk factors related to diarrhea especially in children under five years old, the aim of this study to identify hygiene and sanitation risk factors of diarrheal disease in children less than five years of age in Sulaimani city, Iraq.

\section{Objectives of the study}

1. To assess the risk factors for diarrhea in terms of hygiene and sanitation practices.

2. To find out the association between sociodemographic characteristics of mothers and their children with diarrhea

3. To find out the association between hygiene and sanitation practice with diarrhea

\section{METHOD}

\section{-Design of the Study}

A quantitative design "descriptive" study casecontrol approach was carried out to achieve the objectives of study among participants.

\section{-Setting of the Study}

The present study was conducted at Dr. Jamal Ahmad Rashid Pediatric Teaching Hospital in Sulaimani City.

\section{-Sample of the Study}

A non-probability purposive sample of (105) children was definitely diagnosed with acute diarrhea in pediatric wards, and (105) children were selected as control group in outpatient unit in the same hospital that was not suffering from diarrhea for the last month.

\section{-Criteria of the Study Sample}

1. Patients diagnosed with acute diarrhea.

2. Child under five years old and both genders.

3. Mothers were willing to participate in the study.

\section{-The study instrument}

In order to collect the proper data, questionnaire form was developed by researcher based on related review of literature, and previous studies, to measure the variables underline the present study. It consists of three parts:-

Part one: Socio-demographic characteristics of mother consist of (6) items, which include: age, level of education, occupation, residency, financial status, and family size. 
Part two: Socio-demographic characteristics of children consist of (5) items, which include: age, gender, birth order, birth weight, and vaccination status.

Part three: Sanitation and hygiene practice consist of (9) items include: methods of child defecation, methods of cleaning child after defecation, washing child hands before eating, mother washing hands after toilet, mother washing hands after cleaning child perineum, mother washing hands before feeding child, mother washing hands before preparing food, methods of storing food for later use, and having domestic animals. The SPSS (version 21) was used for the data analysis. The demographic characteristics of the samples were reported by using descriptive statistics (frequencies, percentages, and mean) and chi-square test used for associations.

\section{-Validity of the study tools}

Content validity of the questionnaire was determined through a panel of (15) experts of different specialties. All experts agreed that the questionnaires were clear, relevant and adequate. Minor changes were employed based on their recommendations and suggestions.

\section{-Pilot study}

A pilot study was conducted on a purposive sample of ten children with acute diarrhea in same hospital. The sample of the pilot study was excluded from the present study sample.

The purpose of the pilot study was:

1. To enhance the reliability of the questionnaire.

2. To determine the clarification items of the questionnaire for the respondents.

3. To determine the average time required for data collection.

\section{-Data Collection}

Before interviewing the mothers, an introduction was given and the purpose of the study was explained personally by the researcher to the subjects and to achieve verbal informed consent. Face to face interview was held by researcher and data was collected by using the constructed questionnaire from the period 3rd of March 2021 to $3 r d$ of June $2021 \ldots$

\section{Statistical analysis}

The collected data were compiled and analysed using percentages, mean, median, and Chi-square tests using SPSS version 20. $P$ values of 0.05 were used as a cut-off point for the significance of the statistical test.

\section{RESULTS}

Table (1) shows that $42.9 \%$ of mothers in both case and control groups their ages ranged between (25-34) years old, with mean ages $28.8 \pm 7.2,31.4 \pm 7.5$ respectively. In regard to the level of education, $39 \%$ of mothers in case group were graduated from primary school, $36.2 \%$ of mothers in control group were graduated from secondary school. About mother's occupation in both case and control groups $86.7 \%, 77.1 \%$ of mothers were unemployed respectively. More than half $55.3 \%$ of mothers in case were insufficient, $41 \%$ of mothers in control group were barely sufficient. Regarding residency, $62.9 \%$ of samples in case group, $50.5 \%$ in control groups were living urban area. According to family size $74.3 \%$ of samples in case group and $72.4 \%$ in control group their families consist of less than five members and the rest of families consist of five or more members.

Table (2) about half $49.5 \%$ of children in case group their age were 12 months or younger with mean age $20.5 \pm 16.2$, and about one-third $35.3 \%$ of children in control group their age ranged between 13-24 months with mean age $23.5 \pm 16$. In diarrheal group more than half $53.3 \%$ of children were male but in non-diarrheal group $60 \%$ of children were female. Regarding birth order, $34.3 \%$ and $30.5 \%$ in case and control groups were second birth order. About two-thirds of children in both groups were born with normal birth weight which accounts for $69.5 \%$ and $64.8 \%$ respectively. The majority of sample in both groups were complete vaccination according to age which accounts for $89.5 \%$, and $91.4 \%$ respectively.

Table (3) shows that $67.6 \%$ of children in case, $59 \%$ of children in control group were using diaper, $21.9 \%$ of children in case group, $34.3 \%$ of children in control group were using toilet. More than two-thirds $71.4 \%$ of children in control group and more than half $58.1 \%$ of children in case group were used water for cleaning children after defecation. Highest percentage of mothers in case and control groups $76.2 \%$, and $89.5 \%$ were usually washing their hands after toilet, $62.9 \%$ and $81.9 \%$ in case and control group of mothers were usually washing hands after cleaning child's bottom, $55.2 \%$, and $72.4 \%$ of mothers in case and control group were usually washing their hands before feeding, $70.5 \%$ in case and $79 \%$ in control were usually washing hands before preparing food for their children. The highest percentage of samples were stored food in refrigerator for later use which accounts for $57.2 \%$ and $69.5 \%$ respectively, finally, $83.8 \%$ and $78.1 \%$ of samples in both case and control groups had no domestic animals. 
Table (4) shows significant associations were found between socio-demographic characteristics of mothers with diarrhea in terms of age, level of education, and economic status, while no significant associations were found between occupation, residency, and family size with diarrhea.

Table (5) shows significant associations were found between socio-demographic characteristics of children with diarrhea in terms of age and gender, while no significant associations were found between birth order, birth weight, and vaccination status with diarrhea.

Table (6) shows significant associations were found between sanitation and hygiene practice with diarrhea in terms of clean child's after defecating, mother washing hands after toileting, after cleaning child's bottom, before feeding child and methods of storing food for later use, while no significant associations were found between methods of child defecation, mother washing hands before preparing food and having domestic animals with diarrheal group.

Table 1. Distribution of sample according to mother's sociodemographic characteristics

\begin{tabular}{|c|c|c|c|}
\hline \multirow[t]{2}{*}{ Variable } & \multirow[t]{2}{*}{ Item } & Case & Control \\
\hline & & F (\%) & F (\%) \\
\hline \multirow[t]{4}{*}{ Age (years) } & $18-24$ & $37(35.2)$ & $22(21.0)$ \\
\hline & $25-34$ & $45(42.9)$ & $45(42.9)$ \\
\hline & $\geq 35$ & $23(21.9)$ & $38(36.1)$ \\
\hline & Mean \pm SD & $28.8 \pm 7.2$ & $31.4 \pm 7.5$ \\
\hline \multirow[t]{4}{*}{ Level of education } & Illiterate & $17(16.2)$ & $9(8.6)$ \\
\hline & Primary school & $41(39.0)$ & $28(26.7)$ \\
\hline & Secondary school & $26(24.8)$ & $38(36.2)$ \\
\hline & Institute and university & $21(20.0)$ & $30(28.5)$ \\
\hline \multirow[t]{2}{*}{ Occupation } & Employee & $14(13.3)$ & $24(22.9)$ \\
\hline & Unemployed & $91(86.7)$ & $81(77.1)$ \\
\hline \multirow{3}{*}{ Financial status } & Sufficient & $16(15.2)$ & $22(21.0)$ \\
\hline & Barely sufficient & $31(29.5)$ & $43(41.0)$ \\
\hline & Insufficient & $58(55.3)$ & $40(38.0)$ \\
\hline \multirow[t]{3}{*}{ Residency } & Urban & $66(62.9)$ & $53(50.5)$ \\
\hline & Suburban & $28(26.6)$ & $44(41.9)$ \\
\hline & Rural & $11(10.5)$ & $8(7.6)$ \\
\hline \multirow[t]{2}{*}{ Family size } & Less than five & $78(74.3)$ & $76(72.4)$ \\
\hline & Five and more & $27(25.7)$ & $29(27.6)$ \\
\hline Total & & $105(100)$ & $105(100)$ \\
\hline
\end{tabular}

Table 2. Distribution of sample according to child's socio demographic characteristics

\begin{tabular}{|c|c|c|c|}
\hline \multirow[t]{2}{*}{ Variable } & \multirow[t]{2}{*}{ Item } & Case & Control \\
\hline & & F (\%) & $\mathbf{F}(\%)$ \\
\hline \multirow[t]{6}{*}{ Age (months) } & $\leq 12$ & $52(49.5)$ & $30(28.6)$ \\
\hline & $13-24$ & $24(22.8)$ & $37(35.3)$ \\
\hline & $25-36$ & $7(6.7)$ & $10(9.5)$ \\
\hline & $37-48$ & $15(14.3)$ & $18(17.1)$ \\
\hline & $49-60$ & $7(6.7)$ & $10(9.5)$ \\
\hline & Mean \pm SD & $20.5 \pm 16.2$ & $23.5 \pm 16.0$ \\
\hline \multirow[t]{2}{*}{ Gender } & Male & $56(53.3)$ & $41(39.0)$ \\
\hline & Female & $49(46.7)$ & $64(61.0)$ \\
\hline \multirow[t]{4}{*}{ Birth order } & First & $25(23.8)$ & $22(21.0)$ \\
\hline & Second & $36(34.3)$ & $32(30.5)$ \\
\hline & Third & $19(18.1)$ & $27(25.7)$ \\
\hline & Fourth and more & $25(23.8)$ & $24(22.9)$ \\
\hline \multirow[t]{2}{*}{ Birth weight } & Low birth weight & $32(30.5)$ & $37(35.2)$ \\
\hline & Normal birth weight & $73(69.5)$ & $68(64.8)$ \\
\hline \multirow[t]{3}{*}{ Vaccination Status } & Complete for age & $94(89.5)$ & $96(91.4)$ \\
\hline & Incomplete for age & $11(10.5)$ & $9(8.6)$ \\
\hline & Total & $105(100)$ & $105(100)$ \\
\hline
\end{tabular}


Table 3. Distribution of sample according to sanitation and hygiene practice

\begin{tabular}{|c|c|c|c|}
\hline \multirow[t]{2}{*}{ Variable } & \multirow[t]{2}{*}{ Items } & Case & Control \\
\hline & & F (\%) & $F(\%)$ \\
\hline \multirow[t]{3}{*}{ Methods of child defecation } & Diaper & $71(67.6)$ & $62(59.0)$ \\
\hline & Potty & $11(10.5)$ & $7(6.7)$ \\
\hline & Toilet & $23(21.9)$ & $36(34.3)$ \\
\hline \multirow[t]{2}{*}{ Methods of cleaning child after defecation } & With wet tissue & $44(41.9)$ & $30(28.6)$ \\
\hline & With water & $61(58.1)$ & 75(71.4) \\
\hline \multirow[t]{2}{*}{ Mother washing hands after toilet } & Sometimes & $25(23.8)$ & 11(10.5) \\
\hline & Usually & $80(76.2)$ & $94(89.5)$ \\
\hline \multirow[t]{2}{*}{ Mother washing hands after cleaning child perineum } & Sometimes & $39(37.1)$ & 19(18.1) \\
\hline & Usually & $66(62.9)$ & $86(81.9)$ \\
\hline \multirow[t]{3}{*}{ Mother washing hands before feeding child } & Never & $15(14.3)$ & $9(8.6)$ \\
\hline & Sometimes & $32(30.5)$ & $20(19.0)$ \\
\hline & Usually & $58(55.2)$ & $76(72.4)$ \\
\hline \multirow[t]{3}{*}{ Mother washing hands before preparing food } & Never & $12(11.4)$ & $4(3.8)$ \\
\hline & Sometimes & $19(18.1)$ & $18(17.1)$ \\
\hline & Usually & $74(70.5)$ & $83(79.1)$ \\
\hline \multirow[t]{3}{*}{ Methods of storing food for later use } & In refrigerator & $60(57.2)$ & $73(69.5)$ \\
\hline & Unsafe method & $10(9.5)$ & $2(1.9)$ \\
\hline & Not storing food & $35(33.3)$ & $30(28.6)$ \\
\hline \multirow[t]{2}{*}{ Having domestic animals } & Yes & $17(16.2)$ & $23(21.9)$ \\
\hline & No & $88(83.8)$ & $82(78.1)$ \\
\hline Total & & $105(100)$ & $105(100)$ \\
\hline
\end{tabular}

Table 4. Cross-tabulation between socio-demographic characteristics of mothers and diarrhea

\begin{tabular}{|c|c|c|c|c|c|}
\hline \multirow[t]{2}{*}{ Variable } & \multirow[t]{2}{*}{ Item } & $\begin{array}{c}\text { Case } \\
\mathrm{N}=105\end{array}$ & $\begin{array}{l}\text { Control } \\
\mathrm{N}=105\end{array}$ & Total & \multirow[t]{2}{*}{$\begin{array}{l}\text { X2-square } \\
\text { (P- value) }\end{array}$} \\
\hline & & $\mathbf{N}(\%)$ & $\mathbf{N}(\%)$ & & \\
\hline \multirow[t]{3}{*}{ Age (years) } & $18-24$ & $37(62.7)$ & $22(37.3)$ & 59 & \multirow{3}{*}{$\begin{array}{c}X 2=7.502 \\
(0.023)\end{array}$} \\
\hline & $25-34$ & $45(50.0)$ & $45(50.0)$ & 90 & \\
\hline & $\geq 35$ & $23(37.7)$ & $38(62.3)$ & 61 & \\
\hline \multirow[t]{4}{*}{ Level of education } & Illiterate & $17(65.4)$ & $9(34.6)$ & 26 & \multirow{4}{*}{$\begin{array}{c}X 2=8.749 \\
(0.033)\end{array}$} \\
\hline & Primary school & $41(59.4)$ & $28(40.6)$ & 69 & \\
\hline & Secondary school & $26(40.6)$ & $38(59.4)$ & 64 & \\
\hline & Institute and university & $21(41.2)$ & $30(58.8)$ & 51 & \\
\hline \multirow[t]{2}{*}{ Occupation } & Employee & $14(36.8)$ & $24(63.2)$ & 38 & \multirow{2}{*}{$\begin{array}{c}x 2=3.213 \\
(0.073)\end{array}$} \\
\hline & Unemployed & $91(52.9)$ & $81(47.1)$ & 172 & \\
\hline \multirow[t]{3}{*}{ Financial status } & Sufficient & $16(42.1)$ & $22(57.9)$ & 38 & \multirow{3}{*}{$\begin{array}{c}\times 2=6.199 \\
(0.045)\end{array}$} \\
\hline & Barely sufficient & $31(41.9)$ & $43(58.1)$ & 74 & \\
\hline & Insufficient & $58(59.2)$ & $40(40.8)$ & 98 & \\
\hline \multirow[t]{3}{*}{ Residency } & Urban & $66(55.5)$ & $53(44.5)$ & 119 & \multirow{3}{*}{$\begin{array}{c}x^{2}=5.449 \\
(.0066)\end{array}$} \\
\hline & Suburban & $28(38.9)$ & $44(61.1)$ & 72 & \\
\hline & Rural & $11(57.9)$ & $8(42.1)$ & 19 & \\
\hline
\end{tabular}




\begin{tabular}{|c|c|c|c|c|c|}
\hline \multirow[t]{2}{*}{ Family size } & Less than five & $78(51.0)$ & $51(49.0)$ & 153 & \multirow[t]{2}{*}{$\begin{array}{c}X 2=0.217 \\
(.0642)\end{array}$} \\
\hline & Five and more & $27(47.4)$ & $30(52.6)$ & 57 & \\
\hline
\end{tabular}

Table 5. Cross tabulation between socio-demographic characteristics of child and diarrhea

\begin{tabular}{|c|c|c|c|c|c|}
\hline Variable & Item & $\begin{array}{c}\text { Case } \\
\mathrm{N}=105 \\
\mathrm{~N}(\%)\end{array}$ & $\begin{array}{c}\text { Control } \\
\mathrm{N}=105\end{array}$ & Total & $\begin{array}{l}\text { X2-Squar } \\
\text { (P- value) }\end{array}$ \\
\hline \multirow[t]{5}{*}{ Age (months) } & $\leq 12$ & $52(63.4)$ & $30(36.6)$ & 82 & \multirow{5}{*}{$\begin{array}{c}x 2=10.004 \\
(0.040)\end{array}$} \\
\hline & $13-24$ & $24(39.3)$ & $37(60.7)$ & 61 & \\
\hline & $25-36$ & $7(41.2)$ & $10(58.8)$ & 17 & \\
\hline & $37-48$ & $15(45.5)$ & $18(54.5)$ & 33 & \\
\hline & $49-60$ & $7(41.2)$ & $10(58.8)$ & 17 & \\
\hline \multirow[t]{2}{*}{ Gender } & Male & $56(57.7)$ & $41(42.3)$ & 97 & \multirow{2}{*}{$\begin{array}{c}X^{2}=4.311 \\
(0.038)\end{array}$} \\
\hline & Female & $49(43.4)$ & $64(56.6)$ & 113 & \\
\hline \multirow[t]{4}{*}{ Birth order } & First & $25(53.2)$ & $22(46.8)$ & 47 & \multirow{4}{*}{$\begin{array}{c}X^{2}=1.838 \\
(0.607)\end{array}$} \\
\hline & Second & $36(52.9)$ & $32(47.1)$ & 68 & \\
\hline & Third & $19(41.3)$ & $27(58.7)$ & 46 & \\
\hline & Fourth and more & $25(51.0)$ & $24(49.0)$ & 49 & \\
\hline \multirow[t]{2}{*}{ Birth weight } & Low birth weight & $32(46.4)$ & $37(53.6)$ & 69 & \multirow{2}{*}{$\begin{array}{c}X 2=0.540 \\
(.0463)\end{array}$} \\
\hline & Normal birth weight & $73(51.8)$ & $68(48.2)$ & 141 & \\
\hline \multirow[t]{2}{*}{ vaccination status } & Complete for age & $94(49.5)$ & $96(50.5)$ & 190 & \multirow{2}{*}{$\begin{array}{c}X 2=0.221 \\
(.0638)\end{array}$} \\
\hline & Incomplete for age & $11(55.0)$ & $9(45.0)$ & 20 & \\
\hline
\end{tabular}

Table 6. Cross tabulation between sanitation and hygiene practice and diarrhea

\begin{tabular}{|c|c|c|c|c|c|}
\hline \multirow[t]{2}{*}{ Variable } & \multirow[t]{2}{*}{ Item } & \multirow{2}{*}{$\begin{array}{l}\text { Case } \\
\mathrm{N}(\%)\end{array}$} & \multirow{2}{*}{$\begin{array}{l}\text { Control } \\
\text { N (\%) }\end{array}$} & \multirow[t]{2}{*}{ Total } & \multirow[t]{2}{*}{$\begin{array}{l}\text { X2-Squar } \\
\text { (P-value) }\end{array}$} \\
\hline & & & & & \\
\hline \multirow[t]{3}{*}{ Method of child defecation } & Diaper & $71(53.4)$ & $62(46.6)$ & 133 & \multirow{3}{*}{$\begin{array}{c}X 2=4.362 \\
(0.113)\end{array}$} \\
\hline & Potty & $11(61.1)$ & $7(38.9)$ & 18 & \\
\hline & Toilet & $23(39.0)$ & $36(61.0)$ & 59 & \\
\hline \multirow[t]{2}{*}{ Methods of cleaning child after defecation } & With wet tissue & $44(59.5)$ & $30(40.5)$ & 74 & \multirow{2}{*}{$\begin{array}{r}x 2=4.90 \\
(0.043)\end{array}$} \\
\hline & With water & $61(44.9)$ & $75(55.1)$ & 136 & \\
\hline \multirow{2}{*}{ Mother washing hands after toilet } & Sometimes & $25(69.4)$ & $11(30.6)$ & 36 & \multirow{2}{*}{$\begin{array}{c}x 2=6.571 \\
(0.010)\end{array}$} \\
\hline & Usually & $80(46.0)$ & $94(54.0)$ & 174 & \\
\hline \multirow{2}{*}{$\begin{array}{l}\text { Mother washing hands after cleaning child } \\
\text { perineum }\end{array}$} & Sometimes & $39(67.2)$ & $19(32.8$ & 58 & \multirow{2}{*}{$\begin{array}{c}x 2=9.528 \\
(0.002)\end{array}$} \\
\hline & Usually & $66(43.4)$ & $86(56.6)$ & 152 & \\
\hline \multirow[t]{3}{*}{ Mother washing hands before feeding child } & Never & $15(62.5)$ & $9(37.5)$ & 24 & \multirow{3}{*}{$\begin{array}{c}x 2=6.687 \\
(0.035)\end{array}$} \\
\hline & Sometimes & $32(61.5)$ & $20(38.5)$ & 52 & \\
\hline & Usually & $58(43.3)$ & $76(56.7)$ & 134 & \\
\hline \multirow{3}{*}{$\begin{array}{l}\text { Mother washing hands before preparing } \\
\text { food }\end{array}$} & Never & $12(75.0)$ & $4(25.0)$ & 16 & \multirow{3}{*}{$\begin{array}{c}x 2=4.543 \\
(0.103)\end{array}$} \\
\hline & Sometimes & $19(51.4)$ & $18(48.6)$ & 37 & \\
\hline & Usually & $74(47.1)$ & $83(52.9)$ & 157 & \\
\hline \multirow[t]{3}{*}{ Methods of storing food for later use } & In refrigerator & $60(45.1)$ & $73(54.9)$ & 133 & \multirow{3}{*}{$\begin{array}{c}x 2=6.989 \\
(0.030)\end{array}$} \\
\hline & Unsafe method & 10(83.3) & $2(16.7)$ & 12 & \\
\hline & No stored & $35(53.8)$ & $30(46.2)$ & 65 & \\
\hline Having domestic animals & Yes & $17(42.5)$ & $23(57.5)$ & 40 & $\begin{array}{c}X 2=1.112 \\
(0.292)\end{array}$ \\
\hline
\end{tabular}




\section{DISCUSSION}

Part one: Sociodemographic characteristics of mothers and their children

Based on the findings of the current study, less than half of the mothers belonged to the age group between (25-34) years. A study conducted at Saudi Arabia showed that found that $54.6 \%$ of mothers were between (25-34) years old (Shati et al., 2020).

About level of education of mothers, more than one-third were graduated from primary school, approximately one-quarter of mothers were graduated from secondary school and majority of mothers were unemployed. This results in agreement with study conducted in Baghdad they found that highest percentage of mothers were uneducated and highest percentage of mother in their study was unemployed (Alaa et al., 2014).

Concerning residency highest percentage of sample were livings in urban area. This finding is consistent with a previous study conducted in Yemen by Bahartha and AlEzzi, (2015) which showed that $61 \%$ of samples lived in urban and $39 \%$ in rural areas.

Approximately three-quarter of the sample their families consist of less than five members, the result of current study disagree with the findings of the study done by Tesfaye et al.,(2020) reported that the child in households of family members greater than five more likely to suffer diarrhea. This could be due to the fact that family size in Sulaimani city is smaller than in other cities of Iraq, since the present study was conducted in Sulaimani city and most of the samples were living in an urban area.

Regarding child's socio-demographic characteristics about half of children their ages were 12 months or younger with mean age $(20.5 \pm 16.2)$. This finding in line with the finding of the study done by Bahartha \& AlEzzi., (2015) they found the same results most of the children were under the age of one year old. In terms of child gender more than half of sample were male. This result were agree with the study done by Pisey et al., (2020) they found that more than half of the children were male.

According to birth order more than one-third of the children were second birth order. This findings agree with the study done by Mihrete et al., (2014) they mentioned that $30.7 \%$ of children 2 or 3 birth order, being the second or third child had about three times more likely to have diarrhea compared to being the first child.

In regard to birth weight highest percentage of children were born with normal birth weight, which accounts for $69.5 \%$. This is consistent with the study of Oloruntoba, et al. 2014 they found that $68.2 \%$ of children were born with normal birth weight.

The majority of children were received complete vaccination according to age, this finding consistent with a study conducted by Dairo et al.,
(2017) found that $84.6 \%$ of the study sample were fully vaccinated according to their age.

Part two: risk factors of diarrhea in terms of sanitation and hygiene practice

Concerning sanitation and hygiene practice, highest percentage of children were using diaper, which accounts $67.6 \%$. This result is consistent with Udeh's et al., 2021 study found that $69 \%$ of children used diaper.

Regarding methods of cleaning children after defecate more than half which accounting highest percentages of children were using water for cleaning of their child after defecating, according to a study conducted in Nigeria by Florence et al., (2017) they found that $85 \%$ of mothers used only water for cleaning child after defecating. .

Regarding mothers hand washing at 4 critical times 76.2 of mothers were usually washing their hands after toilet, $62.9 \%$ of mothers were usually washing their hands after cleaning child perineum, $55.2 \%$ of mothers were usually washing their hands before feeding, and $70.5 \%$ of mothers were usually washing their hands before preparing food respectively. This is in line with Florence et al., (2017) findings, that shows nearly the same results, $94.5 \%$ of mothers were usually washing their hands after toilet, $73.5 \%$ of mothers usually were washing their hands after cleaning child perineum, $56.3 \%$ of mothers were usually washing their hands before feeding child, but the results of the same study disagree with present study in term of mothers washing their hands before preparing food for the child.

In regard to storing foods for later use, the highest percentages of samples were stored food in the refrigerator for later use. This finding is inconsistent with the study Florence et al., 2017 found that $26 \%$ of samples stored food in the refrigerator for later use. Furthermore, the availability of using refrigerator as a food preservation source was statistically linked to a low occurrence of diarrhea (Al-Hindi, 2017).

In regard domestic animal the majority of sample no having domestic animals. This result agreed with the study done by Degebasa et al., (2018) who found that highest percentage of families did not have animals at home.

Part three: association between socio demographic characteristics of mothers and their children in case and control groups.

Significant associations were found between diarrhea and sociodemographic characteristics of mothers in terms age of mother, level of education, and financial status, it means that young and low educated of mothers, insufficient financial status are at more risk of diarrhea in children under five years old. Children whose mothers were younger more likely to have child diarrhea compared to those from older age mothers, which is consistent with study done by Edwin, and Azage, (2019) they found significant associations were found between young mothers ages and diarrheal occurrence among under five children, as mother's age increased, the risk of 
diarrhea for the under five children decreased. The finding agree with a previous study conducted by Alaa et al., 2015 in Baghdad found a significant association between uneducated mothers with diarrhea. The prevalence of diarrhea differs depending on the education of the mother, children of secondary or higher educated mothers suffering less diarrhea than children of mothers with illiterate or primary school graduates (Boadi and Kuitunen et al.,2005).

The current study revealed that significant associations were found between insufficient financial status of family and diarrhea, which is supported by a study conducted by Kalakheti et al. (2016), who reported that the low economic status of the family was significant with the occurrence of diarrhea in children under five years old. Children from families with poor economic status had a higher risk than children from middle and good economic status, this could be attributed to poor hygiene and sanitation, a lack of clean water, a lack of awareness about diarrhea prevention, improper stool disposal, and living in an unsafe environment (Habtu et al., 2017).

Significant associations were found between a child's sociodemographic characteristics and diarrhea in terms of age and gender, which means that infant and male gender are at more risk of diarrhea in children under five years old. This result supported by Shimelis et al., (2008) they found were significant association were found between infant age and diarrhea. The high prevalence of diarrhea among this age could be explained by fact the child starts crawling at this age and the risk of ingesting contaminated materials such as soil, or due to cessation of breast feeding and introducing of bottle feeding in the early months of life (Mutama et al., 2019; Bahartha \& AlEzzi 2015).Similar pattern was reported by Mutama et al., 2019 found significant association between males and diarrhea. Boys were more than two times more likely to be affected by diarrheal disease than girls among the participants in their study.

Part four: association between case and control groups in regard to sanitation and hygiene practice

significant associations were found between sanitation and hygiene practice with diarrhea in terms of methods of cleaning child after defecation, mother washing hands after toilet, mother washing hands after cleaning child's bottom, mother washing hands before feeding child and methods of storing food for later use, it means that wet tissue used to clean child's after defecation, sometimes wash child's hands before eating, sometimes mothers washing hands after toileting, sometimes mothers washing hands after cleaning child's bottom, sometimes mothers washing hands before feeding child and unsafe method of storing food for later use are at more risk of diarrhea in children under five years old.
Regarding washing hands of mothers, this result is confirmed by Oloruntoba (2014), which reported that significant association between mothers often wash hands before feeding and diarrhea in their children, also found that significant association between mothers often wash hands after toilet and diarrhea in their children. Solomon et al., (2020) they found that significant association between mothers who do not wash hands after cleaning child's bottom, and mentioned that children of mothers who did not wash their hands after contact with child feces were six times more likely to develop a diarrheal disease than their counterparts. Another updated review of the evidence linking interventions of the promotion of hand hygiene and diarrhea morbidity showed a $40 \%$ reduction in diarrhea (Freeman et al., 2014).

The current study indicated there is significant association were found between unsafe methods of stored food for later use and diarrhea, this result supported by a study from Vietnam that reported significant association between unsafe methods of stored food for later use and diarrhea (Bui, 2006).

\section{CONCLUSIONS}

Young and low educated mother, low family income, infant age, male gender, poor hygiene practice, were the main risk factors of diarrhea. To minimize the rate of childhood diarrhea, there is a need to improve awareness of mothers regarding sanitation and personal hygiene and rotavirus vaccination.

\section{ETHICAL CONSIDERATIONS COMPLIANCE WITH ETHICAL GUIDELINES}

The protocol of the study was accepted by the council of the College of Nursing and approved by the ethical committee of the College of Medicine / University of Sulaimani. An official letter has been submitted from the College of Nursing to Sulaimani General Directorate of Health in order to obtain facilitation and cooperation, consequently, an agreement letter has been submitted from Sulaimani General Directorate of Health to Dr. Jamal Ahmed Rashid Pediatric Teaching Hospital.

\section{FUNDING}

This research did not receive any grant from funding agencies in the public, commercial, or non-profit sectors.

\section{AUTHOR'S CONTRIBUTIONS}

Study concept; Writing the original draft;D ata collection; Data analysis and Reviewing the final edition by all authors.

DISCLOSURE STATEMENT: The authors report no conflict of interest. 


\section{ACKNOWLEDGEMENTS}

We thank the anonymous referees for their useful suggestions.

\section{REFERENCES}

Alaa, H., Shah, S. and Khan, A., 2014. Prevalence of diarrhoea and its associated factors in children under five years of age in Baghdad, Iraq. Open Journal of Preventive Medicine, 04(01), pp.17-21. Alam, N.H., Meier, R., Schneider, H., Sarker, S.A., Bardhan, P.K., Mahalanabis, D., Fuchs, G.J. and Gyr, N., 2000. Partially hydrolyzed guar gumsupplemented oral rehydration solution in the treatment of acute diarrhea in children. Journal of pediatric gastroenterology and nutrition, 31(5), pp.503-507.

Al-Hindi, A., 2017. Epidemiology of acute diarrheal diseases among children under five in Gaza strip: post war community based study. Scholars Journal of Applied Medical Sciences, 5(2) pp.442-452.

Al-Kubaisy, W., Al Badre, A., Al-Naggar, R.A. and NI, N.S., 2015. Epidemiological study of bloody diarrhoea among children in Baghdad, Iraq. International Archives of Medicine, 8.pp.1-9.

Bahartha, A.S. and AlEzzi, J.I., 2015. Risk factors of diarrhea in children under 5 years in Al-Mukalla, Yemen. Saudi medical journal, 36(6), p.720..

Black, R., Allen, L., Bhutta, Z., Caulfield, L., de Onis, M., Ezzati, M., Mathers, C. and Rivera, J., 2008. Maternal and child under nutrition: global and regional exposures and health consequences. The Lancet, 371(9608), pp.243-260.

Boadi, K. and Kuitunen, M., 2005. Childhood diarrheal morbidity in the Accra Metropolitan Area, Ghana: socio economic, environmental and behavioral risk determinants. Journal of Health \& Population in Developing Countries, 7(1), pp.1522.

Bui, H., 2006. The most common causes of and risk factors for diarrhea among children less than five years of age admitted to Dong Anh Hospital, Hanoi, Northern Vietnam (Master's thesis), p.55.

Dairo, M.D., Ibrahim, T.F. and Salawu, A.T., 2017. Prevalence and determinants of diarrhoea among infants in selected primary health centres in Kaduna north local government area, Nigeria. Pan African Medical Journal, 28(1), pp.151-151.

Degebasa, M., Dawit, Z. and Marama, M., 2018. Diarrheal status and associated factors in under five years old children in relation to implemented and unimplemented community-led total sanitation and hygiene in Yaya Gulele in 2017.
Pediatric Health, Medicine and Therapeutics, Volume 9(5), pp.109-121.

Edwin, P. and Azage, M., 2019. Geographical variations and factors associated with childhood diarrhea in Tanzania: a national population based survey 2015-16. Ethiopian journal of health sciences, 29(4), pp.513-024.

Florence Nwaoha A, Chima Ohaeri C, Charles Amaechi E. Prevalence of diarrhoea, and associated risk factors, in children aged 0-5 years, at two hospitals in Umuahia, Abia, Nigeria. Cuadernos de Investigación UNED. 2017 Jun; 9(1):7-14.

Freeman, M., tocks, M., Cumming, O., Jeandron, A., Higgins, J. et al., 2014.Systematic review: hygiene and health: systematic review of handwashing practices worldwide and update of health effects. Tropical Medicine \& International Health, 19(8), pp.906-916

Habtu, M., Nsabimana J., Mureithi C., 2017.Factors Contributing to Diarrheal Diseases among Children Less than Five Years in Nyarugenge District, Rwanda. J Trop Dis 5(2), p. 238.

Harb, A., O'dea, M., Hanan, Z.K., Abraham, S. and Habib, I., 2017. Prevalence, risk factors and antimicrobial resistance of Salmonella diarrhoeal infection among children in Thi-Qar Governorate, Iraq. Epidemiology \& Infection, 145(16), pp.34863496.

Kalakheti, B., Panthee, K. and Jain, K., 2016. Risk factors of diarrhea in children under five years in urban slums: An epidemiological study. Journal of Lumbini medical college, 4(2), pp.94-98.

Kosek, M., Bern, C., \& Guerrant, R., 2003. The global burden of diarrhoeal disease, as estimated from studies published between 1992 and 2000. Bulletin of the world health organization, 81 (3), pp. 197-204.

Lafta, S.F., Al-Charrakh, A.H. and Abd, A.A.J., 2019. PREVALENCE AND MOLECULAR CHARACTERIZATION OF ROTAVIRUS A IN PEDIATRIC PATIENTS WITH ACUTE DIARRHEA. Euromediterranean Biomedical Journal, 14.pp.65-9

Mihrete, T., Alemie, G., Teferra, A., 2014. Determinants of childhood diarrhea among underfive children in Benishangul Gumuz regional state, nort west Ethiopia. BMC pediatrics, 14(1), pp.1-9.

Mutama , R., Mokaya , D., Wakibia, J., 2019.Risk Factors Associated with Diarrhea Disease among Children Under-Five Years of Age in Kawangware Slum in Nairobi County, Kenya, Food and Public Health, 9 (1), pp.1-6. 
Oloruntoba, E., Folarin, T. and Ayede, A., 2014. Hygiene and sanitation risk factors of diarrhoeal disease among under-five children in Ibadan, Nigeria. African health sciences, 14(4), pp.10011011

Pisey V, Banchonhattakit P, Laohasiriwong W. The association of socio-demographic and environmental factors on childhood diarrhea in Cambodia. F1000Research. 2021 Apr 12;9:303.

Rahi, A.A., Magda, A. and Al-Charrakh, A.H., 2013. Prevalence of Cryptosporidium parvum among children in Iraq. American Journal of Life Sciences, 1(6), pp.256-260.

Rashid JA, AlKhalidi MJ, Majeed BA, Saleh KH. Causes of death among hospitalized children under 5 years of age in Sulaymani Pediatrics Teaching Hospital. Iraqi journal of medical sciences. 2009 1; 7(1).

Shamki, J.A., Al-Charrakh, A.H. and Al-Khafaji, J.K., 2012. Detection of ESBLs in Enteropathogenic $E$. coli (EPEC) isolates associated with infantile diarrhea in Kut City. Medical Journal of Babylon, 9(2), pp.403-412.

Shati, A., Khalil, S., Asiri, K., Alshehri, A., Deajim, Y. et al., 2020. Occurrence of diarrhea and feeding practices among children below two years of age in southwestern Saudi Arabia. International journal of environmental research and public health, 17(3), p.722.

Shimelis, D., Benti, D. and Challi, D., 2008. Effect of zinc supplementation in treatment of acute diarrhea among 2-59 months children treated in Black Lion Hospital, Addis Ababa, Ethiopia. Ethiopian Journal of Health Development, 22(2), pp.187-190.

Siziya, S., Muula, A.S. and Rudatsikira, E., 2009. Diarrhoea and acute respiratory infections prevalence and risk factors among under-five children in Iraq in 2000. Italian journal of pediatrics, 35(1), pp.1-9.

Tesfaye, T., Magarsa, A., Zeleke, T., 2020. Moderate to Severe Diarrhea and Associated Factors among Under-Five Children in Wonago District, South Ethiopia:A Cross-Sectional Study. Pediatric Health, Medicine and Therapeutics, 11(2), p.437.

Udeh EO, Chineke HN, Egenti NB, Chizoba AF, Igweagu CP, Nduka C, Adogu PO. Sociodemographic Predictors of Diarrhea Disease Among Under 5 Children, Presenting at a Tertiary Health Facility in Nigeria. Himalayan Journal of Community Medicine and Public Health. 2021 Apr 10;2(2 (In Process)).

UNICEF/WHO, Diarrhoea: Why children are still dying and what can be done, New York: UNICEF; 2009. Available at http://apps.who.int/i ris/bitstream/handle

/10665/44174/

9789241598415 eng. pdf. Accessed 15 March 2018.

Walker, C., Rudan, I., Liu, L., Nair, H., Theodoratou, E., Bhutta, Z., O'Brien, K., Campbell, H. and Black, R., 2013. Global burden of childhood pneumonia and diarrhoea. The Lancet, 381(9875), pp.14051416.

WHO (2017) Diarrheal diseases: Fact sheet [Online]. Available: http://www.who.int/mediacentre/factsheets/fs3 30/en/ [Accessed Jan 5, 2020

Tuky, H., Semender, A., 2019. Assessing risk factors and causative organisms of acute diarrhea in children under 5 years in Al-Hindiya, Karbala, Iraq. Medical Journal of Babylon, 16(4), p.357.

Solomon, E., Gari, S., Kloos, H. and Mengistie, B., 2020. Diarrheal morbidity and predisposing factors among children under 5 years of age in rural East Ethiopia. Tropical Medicine and Health, 48(1), pp.1-10. 